\title{
Operation of Enterprise Resource Planning System Implementation Compatibility Towards Technical Advancement
}

\author{
${ }^{1}$ Venkatesh, J., ${ }^{2}$ C. Aarthy, ${ }^{3}$ S. Thenmozhi and ${ }^{4}$ P. Balasubramanie \\ ${ }^{1}$ Department of Management Studies, \\ Anna University Chennai, Regional Centre Coimbatore, Coimbatore-641 047, Tamil Nadu, India \\ ${ }^{2}$ Department of Management Studies, Anna University Chennai, \\ Regional Centre Coimbatore, 641 047, Coimbatore, Tamil Nadu, India \\ ${ }^{3}$ Department of Computer Applications, Gnanamani College of Technology, \\ AK Sumuthiram, Paachal, Namakkal District, India \\ ${ }^{4}$ Department of Computer Science and Engineering, \\ Kongu Engineering College, Perundurai, Erode-638, Tamil Nadu, India
}

Received 2012-06-10, Revised 2012-09-05; Accepted 2013-04-01

\begin{abstract}
The Execution of ERP systems has been perplexing factor for many firms. Many establishments have accepted that the operation of ERP system is a massive hindrance until the flow of process is organized carefully. As information technology is booming its prerequisite for organizations to realize the prominence of technical advancement and compatibility in work environment. A complete review was done to ascertain the features and strategic aids of ERP enactments using the retorts from 120 firms. The respondents were approached with orderly framed questionnaires, thereby giving them ample time to come out with their own thoughts. The effects of this learning provide assistance for the vendors, higher officials and ERP specialists to be more competent in handling the execution of ERP with their inadequate possessions there by augmenting the business. It acts a pathway for the concerns to realize their potent and extend their business platform.
\end{abstract}

Keywords: Interdependencies, Threats, Project Intricacy, Manufacturing Services

\section{INTRODUCTION}

To be more competitive and carry over a dynamic business environment the existing era requires Ecommerce and business integrated initiatives. This has voluntarily induced the firms to transmit deliberate initiatives to build and withstand business affordability.In 70's the dream of implementing enterprisewide system was quitedifficult due to technology hindrance but at that time "island of automation" (McKinney and McFarlane, 1982) concept was broadly used to compensate the emerging needs of business. Since 1980's the Information and Communication Technology (ICT) based solicitations and electronic media act as promoter for enhancements in business. ICT aids concerns to progress information flow, enhance operative flexibility, helps firms to modernize business operations and assimilate functionalities. But there are substantial records of studies that have contended on businesses not acquiring the feasible fiscal assistance from ICT speculation. Similarly Enterprise Resource Planning (ERP) which is considered as one of the overwhelming ICT applications advocates the same situation. Enterprise Resource Planning methods are broadly used by outsized initiatives to assimilate the business flow and functions into a consolidated structure. Various modules like finance, sales, human resource, supply chain, production Coimbatore-641 047, Tamil Nadu, India 
and customer information are developed and integrated for effective communication and collaboration. On the other hand several readings have exposed that all ERP applications are not effective in refining the efficiency and capabilities of a firm. According to Legare (2002) "ERP operation failure rate is from $30-50 \%$ ", however firms try to implement these structures because they are vital to receptive forecasting and communication. Because of globalization the competition among the firms increases which in turn give pressure for execution of ERP projects in huge numbers. So a practical context which deals with tricky problem of assessing ERP projects is mandatory. It has been found that, exclusive risks in ERP application arise due to interdependencies of business progressions, databases and process reengineering. According to Markus et al. (2000) three main factors that can be responsible for failure of ERP system are: improper planning or poor management; change in business goals during project; and absence of business management support. Both software and business perspective differs each other, i.e., from a software perception ERP systems is comprehensive. But from the business view it is found that software and business procedures need to be associated, which comprises a blend of business process strategy and software alignments. So a procedural method to ERP system design is inadequate. It also facilitates an assessment of the configuration of current processes with those provided by the ERP system. Implementation of ERP in distributed organizations is quite difficult because they repeatedly have diverse procedures, business and data semantics, hierarchies and decision centers. But these enterprise systems act as a pillar for the communication and information control and act as a best business practises for the organization, (Shehab et al., 2004).

According to Markus et al. (2000) a cautious use of communication and adaptable to change is essential to handle the often business progression impact of ERP systems which can relieve some of the hitches, but a more vital issue of concern is the cost feasibility of system integration, training and user licenses, system operation needs to be tested. A vital part of ERP system incorporation process is design interface with a process strategy. The key objective of this study is to study the success factors of ERP execution to reduce the ERP application failure rate among the indigenous companies. Venkatesh and Aarthy (2012) says that the costs involved in implementation and deployment is usually $200-300 \%$ of the cost of the ERP system. The implementation and deployment could heavily involve consulting/technical services from external entities. This added cost could significantly impact the cost management and control of the implementation and deployment project. Due to the complexity of these commercial systems, companies frequently find themselves adopting the business logic/models defined by the software systems, rather than customizing the ERP system to fit the best business logics. When organizations need to change their business models or operation logics, it usually takes long time to implement the changes in the ERP system due to the complexity of the system.

\subsection{Threats in ERP Implementation}

The risks related with the general success of an organizations project were application intricacy, lack of user participation and absence of role clarity of individuals on the project. Absence of user support was substantial for the organizational impact; while technological innovation affected system quality satisfaction. Systems development was affected by the team's general capability, application intricacy and user support and systems use was affected by role clarity and user knowledge. While these previous studies are related, none clearly examined the environment of ERP systems. In order to capitalize on the probability of success, the risks related with a task must be minimized. As stated above, review firms reduce the threat of review failure through the identification of distinctive, control and detection risks followed by the formation of a suitable, specified level of overall assessment risk that is a function of those other risks. The same logic holds for the application of an ERP system. In order to improve the chance of success, the risks must be acknowledged and success factors should be identified to minimize those threats.

Another major risk is project intricacy. An ERP system enactment involves quite large expenses for the procurement of the hardware, software, employment costs, consulting fees and training costs and can last for an prolonged period of time. ERP system application project has a broader scope related to other information system applications and may cause a significant number of changes within an organization. Lack of in house skills is another cause of risk in the implementation of ERP systems. Lack of assignment team capability has often been associated with software development risk. An ERP system implementation project requires a wide range of skills (i.e., change management, BPR) apart from technical implementation knowledge. 


\subsection{Factors for ERP Implementation}

Nah et al. (2001) explored critical success factors for ERP implementation by accompanying a literature review. They found that key management disputes were teamwork, adaptability, top management support, plan and vision, business process management and development, project management, monitoring, effective communication, software development and testing, the role of the project champion and appropriate business and IT legacy systems. According to Nelson and Cheney (2005) 'Effective training' is also an important factor that should be considered for the study, our study also speaks about the importance of training irrespective of age and qualification. Their study shows that the composite organizational change issues must be broadly addressed and that they cannot be overwhelmed by using technical solutions alone. Similarly, Huang et al. (2003; 2004) propose that in addition to emerging technical aspects of ERP, more effort is essential in understanding the more complex organizational issues involved. The frequent speed of change in firms and their atmospheres has ensued in difficult technical organizational, racial and dogmatic disputes that have made the incorporation process a challenging task.

Change management is vital for many multinational companies where other concerns are physically separate. This complication comprises several aspects including commercial policy, software alignment, technical platform and management execution. Among these, management execution subsidizes towards ERP implementation success to a greater extent. Issues related to enterprise-wide implementation on local sites should be controlled by local administration. Cooper and Zmud (1990) say that the execution process consists of six phases: initiation, adoption, adaptation, acceptance, routinization and infusion. IT implementation, IT failures and business process reengineering literatures detects numerous factors that may disturb the ERP execution method and the prospect of renovation success.

\section{MATERIALS AND METHODS}

The research focus of this work is manufacturing firm's services and efficacies. A total of 120 sample firms detail were collected. For content validity and instrument reliability the questionnaire was pilot tested with twenty five firms. Based upon the discrepancy the final survey was sent to respondents in each firm. Data were held by a mail questionnaire. Huber and Powered
(1985) noted that "if only one respondent per organization is to be questioned, try to identify the person most familiar about the issue of interest". The interdepartmental communication was considered to be the most suitable informant because of the easy access of reliant and consistent information. In order to detect the success factors, a total of twenty two questions were used. The respondents were asked to specify their extent on each factor which was significant in their ERP implementation stages. It was measured based on a four point likert scale. The rating scale ranged from: ' 1 Critical', '2-High', '3-Moderate' and '4-Low'. The target defendant in each firm was the information officer, the information systems director, information technology manager or any person responsible for ERP System as they participate directly in ERP system. Table 1 lists out the factors which are taken into account for implementation of ERP. Based on these factors the questionnaires are framed and results obtained. The factors are categorized into three sections as Demographic, interpersonal relationship and operations related factors.

The questionnaire was designed with refernce to Somers and Nelson (2004) who initially designed the Critical success factor model of ERP early in United States. The questionnire starts by recognizing key ideas to examine demographic features of the ownermanager, information about ERP system application. Demographics characteristics were age, qualification level, age of business and implementation. Next set of questions deals with interpersonal relationship and were designed to examine the important factors like thirst to learn new things, proficiency of project team, support from senior team; the final set of questiions addresses the operational efficiency, cost, adaptability of the organization, the final stage was the ranking and analysis of the response data. Data were entered to SPSS for testing the hypotheses. The following methods are used for manipulation of data.

A descriptive analysis was carried out in order to understand the distribution of the responses obtained from the survey. Cross tabulation: Cross tabulation analysis, also known as contingency table analysis and is most often used to analyze categorical (nominal measurement scale) data. A cross-tabulation is a two (or more) dimensional table that records the number (frequency) of respondents that have the specific characteristics described in the cells of the table. Crosstabulation tables provide a wealth of information about the relationship between the variables. 
Table 1. Fctors under study for successful ERP implementation

\begin{tabular}{llll}
\hline Factors & & & \\
\hline & Demographic factors & 12 & Vendor partnership \\
1 & Age of respondents & 13 & Helping steering committees \\
2 & Qualification & 14 & Suggestions considered \\
3 & Implementation stage & & Factors related to operations \\
4 & Age of business & 15 & Operational cost \\
& Interpersonal relationship & 16 & Improved operational efficiency \\
5 & Effective training & 17 & Reduced redundancy of work \\
6 & Opportunity to learn new things & 18 & Adaptable to change to new business \\
7 & Inter departmental communication & 19 & Improved operational flexibility \\
8 & Support from Seniors & 20 & Agile \\
9 & Proficient project team & 21 & ERP functionalities met job requirements \\
10 & Help from consultant & 22 & Improved quality of operations \\
11 & Management's expectation & & \\
\hline
\end{tabular}

A Chi-Square-test was conducted on the dependent and independent variables to identify the statistically significant constructs (if any). The Null and Alternate hypothesis were framed and results were drawn with 0.05 significance value.

\subsection{Finding and Analysis}

The target sample is manufacturing concern and from the study we find out that among the twenty two factors considered the following seven aspects were deliberated to be the most successful factors for ERP implementation. The conclusion is drawn based on the calculation of weighted average method (Table 2) among which interdepartmental communication acts a vital factor for implementation. Effective interdepartmental communication confirms that all departments work together in same situations even when time changes. Change in one department parallel make changes or affects other departments. One department may make a alterations that affects another department. If the major department doesn't communicate those deviations to the other department, there can be misperception, hindrance and anger. Without good Communication among the departments, companies can wind up in confusion, with a lack of enthusiasm among employees and a lack of trust and respect between departments. From the study it's inferred that the majority of the respondents are in the age group of 26-35 and they have completed their under graduation. When we speak about the age of business $80 \%$ of the respondents are in the band width of $5-10$ years of old. With the help of Cross tabulation (Table 3) and with Chi-Square test we frame alternate and null hypothesis and by comparing the tabulated and calculated value it is clear that respondents under UG category states that training is highly effective whereas the professionals stated that training is hectic which is depicted in the Fig.
1. Similarly Fig. 2 depicts the relation between the age of business and improvement in operational efficiency. The respondents who fall under 5-10 years of business stated that their operational effficiency has improved (42\%) to great extent and very low operational efficiency for starters and below 5 year's of business. The analysis says that there is no big difference between the start of business and improvement in operational efficiency. The $87.6 \%$ professional degree holder's shows greater interest in learning new things and with the help of Chi-Square by framing Null $\left(\mathrm{H}_{0}\right)$ and Alternate $\left(\mathrm{H}_{1}\right)$ Hypothesis:
$\mathrm{H}_{0}$ : Educational Qualification is independent on learning new things

$\mathrm{H}_{1}$ : Educational Qualification is dependent on learning new things

Since the calculated value (11.612) is less than the tabulated (16.919) value we reject Alternate $\left(\mathrm{H}_{1}\right)$ Hypothesis. So irrespective of their qualification the respondents show equal interest in learning about new things. $62 \%$ of people with age group of 20-25 extremely full-fill the management's expectation and the same category of people $(59 \%)$ are adaptable to change to new environment (Fig. 3) which is a positive factor to be considered.

\subsection{Future Implications}

In today's competitive business environment ERP systems have become vital strategic tools. This research tries to explore the critical success factors in executing ERP systems in manufacturing firms. In order to further develop the study in this field, several detailed interviews with the managers and the senior staff will be directed to get vision about their involvement in managing threat with ERP implementations. 
Venkatesh, J. et al. / Journal of Computer Science 9 (2): 169-175, 2013

Table 2. Top seven successful factors according to survey

\begin{tabular}{lrrrrrrr}
\hline Factors & 4 & 3 & 2 & 1 & Total & Avg. & Rank \\
\hline Top management support & 7 & 142 & 84 & 52 & 285 & 71.2 & IV \\
Inter department communication & 6 & 118 & 93 & 120 & 337 & 84.5 & I \\
Project team competence & 11 & 154 & 57 & 52 & 274 & 68.5 & VI \\
Vendor support & 7 & 112 & 114 & 76 & 309 & 77.2 & III \\
Effective training & 13 & 56 & 213 & 28 & 310 & 77.5 & II \\
Help from steering committee & 0 & 164 & 99 & 20 & 283 & 70.5 & V \\
Abundant resource & 45 & 70 & 75 & 60 & 250 & 62.5 & VII \\
\hline
\end{tabular}

Table 3. Cross tabulation for qualification vs effective training

\begin{tabular}{|c|c|c|c|c|c|c|}
\hline & & \multicolumn{5}{|c|}{ Effective training } \\
\hline & & Critical & High & Moderate & Low & Total \\
\hline \multirow[t]{5}{*}{ Qualification } & Diploma & 13 & 2 & 0 & 0 & 15 \\
\hline & $\mathrm{UG}$ & 0 & $4 \overline{7}$ & 0 & 0 & 47 \\
\hline & PG & 0 & 18 & 8 & 0 & 26 \\
\hline & Professional & 0 & 0 & 18 & 14 & 32 \\
\hline & Total & 13 & 67 & 26 & 14 & 120 \\
\hline
\end{tabular}

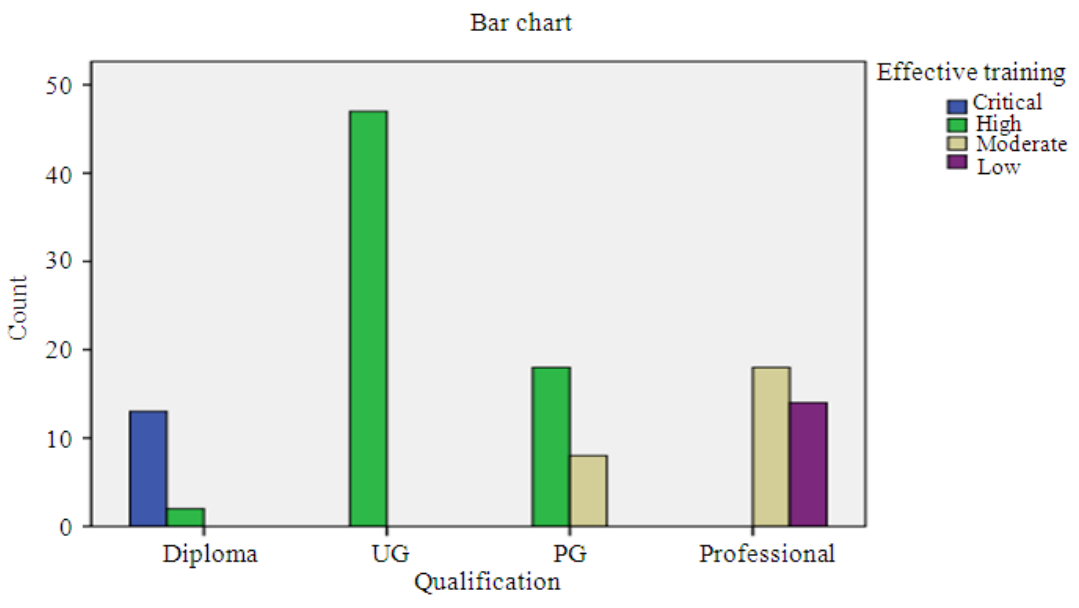

Fig. 1. Chart for educational qualification Vs effective training

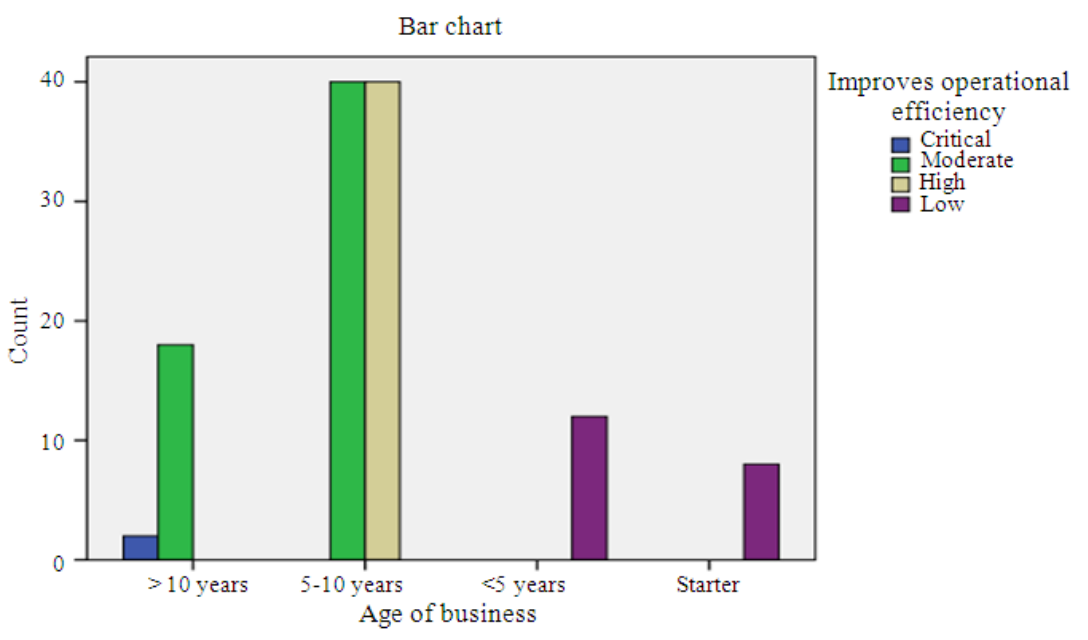

Fig. 2. Representation for age of business vs improved operational efficiency 


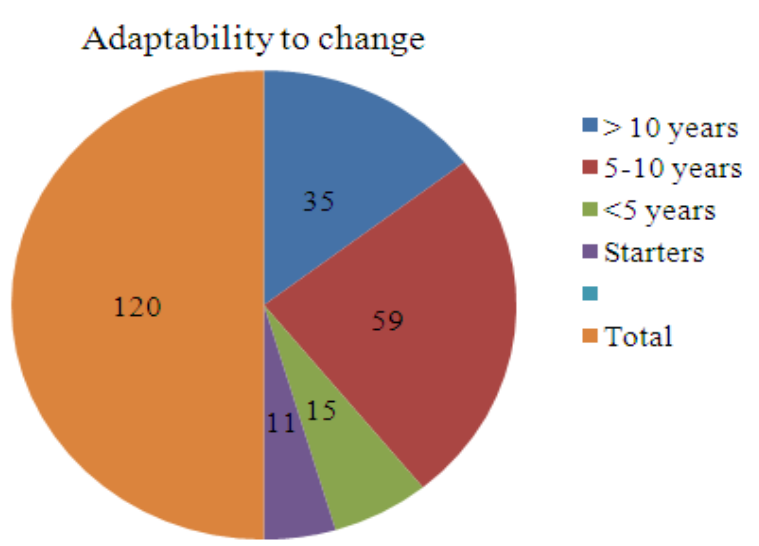

Fig. 3. Illustration for Age vs Employees Adaptability to Change to New Environment

Additionally, most of the scholars seem to have ignored the significant feature of risk management in ERP implementation as most of the research study does not reflect risk management as part of a successful ERP implementation. Though it has been specified previously that some factors are more substantial than others an apt systematic study of interrelationships of success factors reliance is yet to be made. It is told that aspects such as top management support and project competence are not significantly different from factors that are critical to the success of most projects and to organizational change. It is not perfect how these studies promote to a precise understanding of factors critical to the success of ERP projects, as renowned from other types of projects. Also, most of the identified factors are specific to manufacturing industry and there is confusion about whether the identified factors vary across other industry sectors. More research need to be concentrated in more diligence specify success factors. Therefore more effort in these areas should be a focus for future research.

\section{RESULTS AND DISCUSSION}

From the factors taken into account for the study we come to know that inter departmental communication plays a vital role for the co-operative and efficient functioning within the organization. This paves way for reliable and updated information access with in the organization so that the work becomes easy. The respondents say that whatever may be the work they are in need of training and accepted that their organization provides equipped training according to the need of technology growth. The majority of the organizations fall under the band width of 5-10 yrs of age, this shows that they have little experience towards the pros and cons of the business diplomacies. With this experience they overcome the hindrances and establishing themselves with improvement in operational efficiency. The positive factor in the study is majority of the respondents show greater interest in learning about new things which paves way for individual growth as well as organizational progress. Thus the factors like top management support, inter departmental communication, team competence, resources, help from vendor and steering committees and effective training are the key components in execution of ERP systems in an organization

\section{CONCLUSION}

The unexpected growth of the concerns especially the Small and Medium Enterprises has resulted in a reasonably good improvement and a healthy growth rate is anticipated to be constant. The key results of this study would be of worth to the management of the business firms when taking decisions concerning the implementation of ERP. Furthermore, it provides information systems researchers and ERP consultants with better indulgent about the acceptance of ERP systems in the framework of many manufacturing units to confirm successful implementation of ERP. One of the limitations of this study is its confined to a particular sector of business. The findings of this study were narrowed down to manufacturing companies alone. Further analysis and research need to be done on firms from other sectors too. Another limitation is that an extensive range of success factors was not involved due to practical constrictions such as time and cost. The analysis questions have also been summarized to confirm the respondents are not depressed by the number of questions in the questionnaire form. The execution of ERP systems in organizations is a colossally complex undertaking. It is a high-risk project that is essential to be managed and planned properly because it can affect almost every feature of organizational impact and functioning. In this study, a comprehensive list of success factors and vital benefits has been recognized and has been approximately analyzed based on business perspective in employing an ERP system. To ensure success implementation, organizations must learn how to recognize the critical issues that affect the employment process and know when the sequence should be addressed them effectively to confirm that the assured benefits can be apprehended and probable failures can be eluded. 


\section{REFERENCES}

Huang, A., D.C. Yen, D.C. Chou and Y. Xu, 2003. Corporate applications integration: Challenges, opportunities and implementation strategies. J. Bus. Manage., 9: 137-45.

Cooper, R.B. and R.W. Zmud, 1990. Information technology implementation research: A technological diffusion approach. Manage. Sci., 36: 123-139. DOI: $10.1287 / \mathrm{mnsc} .36 .2 .123$

Huang, M.H., J.C. Wang, S. Yu and C.C. Chiu, 2004. Value-added ERP information into information goods: An economic analysis. Indus. Manage. Data Syst., 104: 689-697. DOI: $10.1108 / 02635570410561681$

Huber, G.P. and D.J. Powere, 1985. Retrospective reports of strategic-level managers: Guidelines for increasing their accuracy. Strat. Manage. J., 6: 171180. DOI: $10.1002 / \mathrm{smj} .4250060206$

Legare, T.L., 2002. The role of organizational factors in realizing ERP benefits. Inform. Syst. Manage., 19: $21-42$

DOI: $10.1201 / 1078 / 43202.19 .4 .20020901 / 38832.4$
Markus, M.L., C. Tanis and P.C.V. Fenma, 2000. Enterprise resource planning: Multisite ERP implementations. Commun. ACM, 43: 42-46. DOI: $10.1145 / 332051.332068$

McKinney, J.L. and F.W. McFarlane, 1982. The information archipelago: Maps and bridges. Harvard Bus. Rev., 60: 109-119.

Nah, F.F.H., J.L.S. Lau and J. Kuang, 2001. Critical factors for successful implementation of enterprise systems. Bus. Proc. Manage. J., 7: 285-297. DOI: 10.1108/14637150110392782

Nelson, R.R. and P.H. Cheney, 2005. Training end users: An exploratory study. MIS Q., 11: 547-559. DOI: $10.2307 / 248985$

Shehab, E.M., M.W. Sharp, L. Supramaniam and T.A. Spedding, 2004. Enterprise resource planning: An integrative review. Bus. Process Manage. J., 10: 359-386. DOI: 10.1108/14637150410548056

Somers, T.M. and K.G Nelson, 2004. A taxonomy of players and activities across the ERP project life cycle. Inform. Manage., 41: 257-278. DOI: 10.1016/S0378-7206(03)00023-5

Venkatesh, J. and C. Aarthy, 2012. Investigation of data flow in an ERP environment. Int. J. Market. Technol., 2: 263-271. 